\title{
friedrid) LTaumann
}

Im Zeidbe der $2 \mathfrak{a} \mathfrak{b e i t}$

Tleue unveränderte 2 uflage oer Zusftellungsbriefe

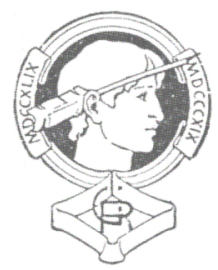

Berlin 1913

Derlag von Georg Reimer 
UIle Recte, insbefondere das der über. fetzung in frembe Sprachen, vorbehalten

Copyright 1909 by Buchverlag der ,Hilfe' GmbH.

Berlin-Schöneberg 